RUNNING HEAD: School Influence and Classroom Control

\title{
School Influence and Classroom Control: A Comparison of Career and Technical Education, Science, and Mathematics Teachers
}

\author{
Bradley Bowen \\ Virginia Polytechnic and State University \\ Adam Marx \\ North Dakota State University \\ Thomas Williams \\ Virginia Polytechnic and State University \\ Larry Napoleon, Jr. \\ North Dakota State University
}

\begin{abstract}
Teacher retention in the STEM fields is of national interest. Several factors, such as job satisfaction, classroom control, and school influence have been linked to teachers leaving the profession. By statistically analyzing various questions from the Schools and Staffing Survey Teacher Questionnaire, this study evaluated the current state of how early career mathematics, science, and career and technical education (CTE) teachers perceive their classroom control and influence over school policy. The results show that CTE teachers perceive they have significantly more influence over school policy than mathematics teachers. CTE teachers also reported having significantly more classroom control than both mathematics and science teachers. By understanding the current state of how CTE perceive school influence and classroom control compared to their mathematics and science teacher counterparts, further research can be conducted to address job satisfaction and teacher retention in the CTE fields.
\end{abstract}

Keywords: Career and Technical Education; Teacher Retention; Classroom Control; School Influence; Schools and Staffing Survey Teacher Questionnaire (SASS TQ)

\section{Introduction}

We have a teacher shortage across most disciplines in the United States; this is not a new phenomenon. As we look to each corner of the country, shortages exist in every state and in every content area (Cross, 2017). Indeed as the baby boomer generation continues to retire en masse, they contribute to the need. However, it appears the supply of newly qualified classroom educators leave the profession early in their careers, compounding the issue (Goldring, Taie, \& Riddles, 2014; Ingersoll, 2002, 2003). Other qualified candidates rarely make it to the classroom beyond the experiences in their teacher preparation program as many choose business and industry positions following graduation, especially within CTE specialties (Ruhland, 2001).

Nationwide, approximately $40 \%$ of teachers across disciplines leave the profession after only four years of teaching (Ingersoll, 2002, 2003). Goldring, Taie and Riddles (2014) reported the generalized findings of the Teacher Follow-up Survey (TFS) administered by the U.S. Department of Education on a roughly four-year cycle since 1988. Across the seven iterations of the TFS, an average of $6.9 \%$ of teachers leave the profession annually. Within the Goldring et al. (2014) report, this accounts for approximately 260,000 teaching positions each year. When looking at those who reported leaving teaching, those who earned less than $\$ 30,000$ annually were the highest 
proportion (14.8\%) of leavers. This group could of course include part time teachers, which also accounted for over $18 \%$ of leavers in the 2012-2013 iteration of the TFS. Of those who left teaching, 28,200 (11\%) reported three or fewer years teaching experience, $35 \%$ of the total leavers had nine or fewer years of experience. Nearly $17 \%$ $(43,300)$ of all leavers specialized in math and science content.

The findings from the TFS highlight many important considerations and raise many questions for the retention of teachers in all content areas; namely, what factors influence teachers to stay in the profession? Early career teachers are more satisfied in their positions if they perceive the opportunity to influence policy at school and work collaboratively in those efforts (Blase \& Kirby, 2009; Boyd et al., 2011; Scribner, Truell, Hager, \& Sricha, 2001; Stockard \& Lehman, 2004; Strong \& Yoshida, 2014). Further, job satisfaction determines early career teachers' decisions to stay in education following their first year (Knobloch \& Whittington, 2002; Liu, 2007; Liu \& Meyer, 2005; Liu \& Ramsey, 2008; Stockard \& Lehman, 2004). Liu (2007) supported this assertion by analyzing the attrition of first year teachers and reported the probability of leaving following the first year decreased by $15 \%$ when early career teachers perceived tangible influence over school policy decision-making. Ruhland (2001) reported that teachers' perceived influence over environmental factors in the school, such as classroom management, institutional climate, and lack of administrative support contributed to early career teachers leaving CTE positions. Effective teaching involves more than lesson planning and classroom performance. Included in this is the sense of autonomy and influence teachers feel within their school environment. This control, in turn, allows teachers the freedom to pursue and incorporate the myriad of effective strategies to engage students. For science teachers, across the literature, this development occurs as a result of quality teacher preparation program experiences, continued professional development, and deliberate mentoring (Davis, Petish, \& Smithey, 2006). The latter of which are fostered and encouraged within the local school where teachers practice their art.

Supporting the need for teachers to feel their opinions are valued and they can enact influence within their schools, the TFS describes many reasons teachers leave. Teachers who left the profession reported gaining more influence and control in their new work environments (Goldring et al., 2014). More than $50 \%$ of leavers reported greater autonomy, more influence over workplace policies, better work/life balance, and preferable procedures for evaluation at new positions outside of teaching (Goldring et al., 2014).

The demands on the advancement of Science, Technology, Engineering, and Mathematics (STEM) across all levels of education are supported by myriad educational initiatives (Cross, 2017). Further, the education and preparation of students through CTE programming is at the forefront of political and practical discussion as well. Preparation in STEM prepares students for the global marketplace (Cross, 2017) and CTE, beyond just careers, prepares students with diverse skills and intangible strategies for success in postsecondary education (Carnevale, Strohl, \& Smith, 2009). In order for any of these educational and societal efforts to come to fruition, we need qualified teachers who ultimately choose to stay in the profession. This research explores the impact teacher influence over school policy and classroom control have in regard to job satisfaction for early career teachers in math, science, and CTE specialties.

\section{Research questions}


This study was guided by two research questions specific to beginning CTE teachers' perceptions of school influence and classroom control when compared to those of beginning science and mathematics teachers. The two questions posed by the researchers were:

1. To what extent are there differences on perceptions of influence over school policy for beginning CTE, science, and mathematics teachers?

2. To what extent are there differences on perceptions of classroom control for beginning CTE, science, and mathematics teachers?

Hypotheses were formulated, where appropriate, and tested to provide specific analyses of Research Question 1 and Research Question 2: a) There is no difference in subject area value for school influence between science teachers and CTE teachers; b) There is no difference in subject area value for school influence between science teachers and mathematics teachers; c) There is no difference in subject area value for school influence between CTE teachers and mathematics teachers; d) There is no difference in subject area value for classroom control between science teachers and CTE teachers; e) There is no difference in subject area value for classroom control between science teachers and mathematics teachers; f) There is no difference in subject area value for classroom control between CTE teachers and mathematics teachers.

\section{Participants}

\section{Method}

Participants were all of the teachers in the survey pool who had less than three years teaching experience and who provided subject-matter codes relating to CTE, science, and mathematics for the Schools and Staffing Survey Teacher Questionnaire (SASS TQ) question, "This school year, what is your MAIN teaching assignment field at THIS school?" were identified and placed in their respective disciplines. Data from the SASS TQ for these groups were extracted and analyzed using descriptive statistics. Teacher demographic data were weighted using the teacher final sampling weight variable. This resulted in 19,190 teachers within the weighted results for CTE, 27,480 for science teachers, and 41,380 for mathematics teachers (see Table 1).

Table 1.

Descriptive Information for Teachers in Each Subject Area.

\begin{tabular}{lccc}
\hline Variable & Science & Mathematics & CTE \\
\hline Weighted Sample & 27,480 & 41,380 & 19,190 \\
Mean Age (years) & 30.23 & 29.25 & 34.27 \\
& $\mathrm{SD}=8.83$ & $\mathrm{SD}=7.85$ & $\mathrm{SD}=10.79$ \\
Mean Teaching Experience (years) & 1.99 & 1.97 & 2.06 \\
& $\mathrm{SD}=0.82$ & $\mathrm{SD}=0.82$ & $\mathrm{SD}=0.82$ \\
Male & $31.9 \%$ & $36.1 \%$ & $48.3 \%$ \\
Female & $68.1 \%$ & $63.9 \%$ & $51.7 \%$ \\
\hline
\end{tabular}

Note: Weighted sample values are rounded to the nearest 10 per IES protocol; SD = standard deviation 


\section{Instrumentation}

The Schools and Staffing Survey (SASS) consists of five questionnaires: a School District Questionnaire, Principal Questionnaire, School Questionnaire, Teacher Questionnaire, and a School Library Media Center Questionnaire. The SASS is conducted by the National Center for Education Statistics (NCES) on behalf of the U.S. Department of Education in order to collect extensive data on American public and private elementary and secondary schools. The SASS provides data on the characteristics and qualifications of teachers and principals, teacher hiring practices, professional development, class size, and other conditions in schools across the nation for a comprehensive picture of elementary and secondary education in the United States. The SASS was designed to produce national, regional, and state estimates for public elementary and secondary schools and related components and is an excellent resource for analysis and reporting on elementary and secondary educational issues (Tourkin et al., 2010).

\section{Sampling Weights}

The SASS survey design required sampling weights allowing researchers to generalize data to the sampled population (Thomas, Heck, \& Bauer, 2005). The sampling weights for elementary, secondary schools, and teachers used in the SASS were provided "to take into account the school's selection probability, to reduce biases that may result from unit non-response, and to make use of available information from external sources to improve the precision of sample estimates" (NCES, 2015) and to help estimate national public school teacher populations and maintain the original sample sizes.

Due to the complexity of the SASS survey design, it employs stratification of data (sampling each subpopulation independently), clustering (teacher selection within schools), and oversampling (over selection of educators containing certain characteristics). Direct estimates of sampling errors, in this type survey, will characteristically underestimate the sampling variability in the summary statistics and distort test of statistical significance (Finster, 2013; Hahs-Vaughn, 2005; Thomas \& Heck, 2001). NCES developed weights to balance this bias and replicate weights for the SASS design to be incorporated in a study to construct unbiased population assessments. Fundamentally, these weights help to summarize and correct for the probability of selection and are inversely proportional to the probability of selection (Finster, 2013; Tourkin et al., 2010).

This study analyzed data from the SASS TQ restricted-use dataset. The purpose of the SASS TQ was to obtain information about teachers, such as education and training, teaching assignment, certification, workload, and perceptions and attitudes about teaching. The methodology included appropriate protocol as required by the NCES and Institute of Education Sciences (IES). Initial restricted-use license access was applied for and authorized by the NCES to Virginia Polytechnic and State University. The access provided a member of the research team with designated single-site user admittance. NCES specific reporting protocols required the results intended for submission be sent to the NCES and IES for approval and authorization for release. The NCES and IES require that weighted all $n$ 's be rounded to the nearest 10 to assure participant anonymity and that all degrees of freedom in statistical tests be rounded to the nearest 10. Therefore, data in tables and the associated narrative may not add to the total $\mathrm{N}$ reported because of rounding requirements.

\section{Variables Analyzed}

Gender, Teaching Experience and Age. The gender of science, mathematics, and CTE teachers was determined by SASS 
RUNNING HEAD: School Influence and Classroom Control

Table 3.

Subject Area Values for School Influence and Classroom Control for Science, Mathematics and CTE Teachers

\begin{tabular}{llllll}
\hline \multicolumn{1}{c}{ Domain } & Mean & SE (Mean) & SD & Minimum & Maximum \\
\hline School Influence & & & & & \\
Science Education & 15.51 & 0.45 & 4.61 & 7 & 28 \\
Mathematics & 15.36 & 0.32 & 4.69 & 7 & 28 \\
CTE & 16.63 & 0.54 & 4.47 & 7 & 28 \\
Classroom Control & & & & & \\
Science Education & 19.16 & 0.34 & 3.08 & 9 & 24 \\
Mathematics & 19.08 & 0.24 & 3.11 & 8 & 24 \\
CTE & 20.99 & 0.24 & 2.95 & 7 & 24 \\
\hline
\end{tabular}

Note: $\mathrm{SE}=$ standard error; $\mathrm{SD}=$ standard deviation

The descriptive statistics show that CTE has a higher mean value for school influence than both science and mathematics, which have similar values. CTE also has a higher mean value for classroom control than does both science and mathematics. Science and Mathematics also have similar values for classroom control. All three domains have similar minimum and maximum values.

T-Tests

Research question 1, "To what extent are there differences on perceptions of influence over school policy for beginning
CTE, science, and mathematics teachers?," was analyzed using t- tests and the results are reported in Table 4 by paired subject areas. The results of the t-tests showed no statistically significant differences between CTE and science teachers or between science teachers and mathematics teachers on perceptions of preparedness. There was a statistically significant difference found between CTE teachers and mathematics teachers (effect size; Cohen's d =0.28). CTE teachers rated themselves as having more school influence than mathematics teachers.

Table 4.

Results from T-Tests for Perceived School Influence

\begin{tabular}{cccccccc}
\hline Subject Area & Mean & Subject Area & Mean & Difference & df & t & p \\
\hline Science Ed. & 15.51 & CTE & 16.63 & 1.12 & 90 & 1.597 & .114 \\
Science Ed. & 15.51 & Math Ed. & 15.36 & 0.15 & 90 & 0.283 & .778 \\
CTE & 16.63 & Math Ed. & 15.36 & 1.27 & 90 & 2.084 & .040 \\
\hline
\end{tabular}

Note: Ed. = Education; $\mathrm{df}=$ degrees of freedom; $\mathrm{t}=\mathrm{t}$-test value; $\mathrm{p}=$ probability level

Research question 2, "To what extent are there differences on perceptions of classroom control for beginning CTE, science, and mathematics teachers?," was analyzed using t- tests and the results are reported in Table 5 by paired subject areas. The results of the t-tests showed no statistically significant differences between science teachers and mathematics teachers on perceptions of classroom control. There was 
a statistically significant difference found between CTE teachers and mathematics teachers on perceptions of classroom control (effect size; Cohen's d=0.63). CTE teachers rated themselves as having more classroom control than mathematics teachers. There was also a statistically significant difference found between CTE teachers and science teachers on perceptions of classroom control (effect size; Cohen's d=0.61). CTE teachers rated themselves as having more classroom control than science teachers.

Table 5 .

Results from T-Tests for Perceived Classroom Control

\begin{tabular}{cccccccc}
\hline Subject Area & Mean & Subject Area & Mean & Difference & df & t & p \\
\hline Science Ed. & 19.16 & CTE & 20.99 & 1.84 & 90 & 4.231 & $<.001$ \\
Science Ed. & 19.16 & Math Ed. & 19.08 & 0.07 & 90 & 0.175 & .862 \\
CTE & 20.99 & Math Ed. & 19.08 & 1.91 & 90 & 5.667 & $<.001$ \\
\hline
\end{tabular}

Note: Ed. $=$ Education; $\mathrm{df}=$ degrees of freedom; $\mathrm{t}=\mathrm{t}$-test value; $\mathrm{p}=$ probability level

\section{Conclusions and Discussion}

The results from this study found that beginning CTE teachers, those with three or fewer years of experience reported a significantly higher level of school influence than did beginning mathematics teachers. There was no significant difference between beginning CTE teachers and beginning science teachers nor between beginning science teachers and beginning mathematics teachers. Therefore, these results demonstrate there are mediating factors providing beginning CTE teachers with a higher perceived level of school influence than beginning mathematics teachers. Results also show a statistically significant difference between the way CTE teachers perceive their level of classroom control compared to their peers who teach mathematics or science. Beginning CTE teachers reported greater perceived classroom control. Similar to school influence, our data analysis show no statistically significant difference between mathematics and science teachers' perception of classroom control.

The results of our analysis could have particular impact on beginning teacher retention. As previously stated, research demonstrates that job satisfaction has an effect on teacher retention (Knobloch \& Whittington, 2002; Liu, 2007; Liu \& Meyer, 2005; Liu \& Ramsey, 2008; Stockard \& Lehman, 2004) and teacher job satisfaction is impacted by perceived school influence (Blase \& Kirby, 2009; Boyd et al., 2011; Scribner, Truell, Hager, \& Sricha, 2001; Strong \& Yoshida, 2014). Therefore, the results of this study demonstrate that beginning CTE teachers may have an improved chance of remaining in the profession longer over their mathematics counterparts. Overall, this is meaningful in regard to perceptions of beginning teachers. However, identifying the specific factors contributing to the significant difference in school influence are beyond the scope of this study.

In many schools, CTE courses are an elective and therefore student success in these courses do not have the same level of emphasis as do the core subjects, such as science and mathematics. In addition, according to the results in Table 1, there are more science and mathematics teachers than CTE teachers within the school. Given these two factors, it is possible that CTE teachers are not required to engage in activities that core subjects teachers are more likely to be 
required to do, such as common planning time and documenting high-stakes standardized testing. Therefore, CTE teachers may feel they have greater flexibility to create an individualized teaching and learning experience. Further, for the most part students choose to enroll in CTE courses offered at most schools. Student's willingness to engage in the learning activities of CTE courses may contribute to teacher's positive perceptions of classroom control. Another possible factor in the reported difference between the way beginning CTE teachers perceive their school influence and classroom control compared to their peers is that standards associated with math and science teachers are often seen as being rigid. This perception is a common one amongst teachers irrespective of content specialty. Conversely, those subjects without the same standards are perceived as lending themselves to greater teacher autonomy.

Again, identifying the exact reasons for the differences in perceptions between CTE teachers and their peers who teach science and mathematics are beyond the scope of this study. While reasons suggested here are plausible, further research is warranted to discern differences within demographic subsets of these groups in addition to the specific criteria influencing the reported level of school influence. Within demographic subsets, potential areas of future research include comparing teachers of different ages, grade levels, or specific CTE content areas. Further research is needed on factors of impact such as pedagogical training, student teaching experiences, or method of certification.

\section{References}

Blase, J., \& Kirby, P. (2009). Bringing Out the Best in Teachers: What Effective Principals Do. Thousand Oaks, CA: Corwin Press.
Boyd, D., Grossman, P., Ing, M., Lankford, H., Loeb, S., \& Wyckoff, J. (2011). The influence of school administrators on teacher retention decisions. American Educational Research Journal, 48(2), 303-333.

Carnevale, A. P., Strohl, J., \& Smith, N. (2009). Help wanted: Postsecondary education and training required. New Directions for Community Colleges, 2009(146), 21-31.

Cross, F. (2017). Teacher shortage areas: Nationwide listing 1990-1991 through 2017-2018. U.S. Department of Education Office of Postsecondary Education. Retrieved from: https://www2.ed.gov/about/offices/list/o pe/pol/tsa.html\#list.

Davis, E. A., Petish, D., \& Smithey, J. (2006). Challenges new science teachers face. Review of Educational Research, 76(4), 607-651.

Finster. (2013). Teachers' job satisfaction, organizational commitment, turnover intentions, and actual turnover: A secondary analysis using an integrative structural equation modeling approach (Doctoral Dissertation). Retrieved from https://digital.lib.washington.edu/researc hworks/handle/1773/23621

Goldring, R., Taie, S., \& Riddles, M. (2014). U.S. Department of Education. Teacher attrition and mobility: Results from the 2012-13 Teacher Follow-up Survey (NCES 2014-077). Washington, DC: National Center for Education Statistics.

Hahs-Vaugh, D. L. (2005). A primer for using and understanding. The Journal of Experimental Education, 73(3), 221248.

Ingersoll, R. M. (2002). The teacher shortage: A case of wrong diagnosis and wrong prescription. NASSP Bulletin, 86(631), 16-31.

Ingersoll, R. M. (2003). Is there really a teacher shortage? The Consortium for 
Policy Research in Education and The Center for the Study of Teaching and Policy; University of Pennsylvania. Retrieved on September 13, 2017 from http://repository.upenn.edu/gse_pubs/13 3

Knobloch, N. A., \& Whittington, M. S. (2002). Novice teachers' perceptions of support, teacher preparation quality, and student teaching experience related to teacher efficacy. Journal of Vocational Education Research, 27(3), 331-341.

Liu, X. S. (2007). The effect of teacher influence at school on first-year teacher attrition: A multilevel analysis of the Schools and Staffing Survey for 19992000. Educational Research and Evaluation, 13(1), 1-16.

Liu, X. S., \& Meyer, J. P. (2005). Teachers' perceptions of their jobs: A multilevel analysis of the Teacher Follow-Up Survey for 1994-95. Teachers College Record, 107(5), 985-1003.

Liu, X. S., \& Ramsey, J. (2008). Teachers' job satisfaction: Analyses of the Teacher Follow-up

Survey in the United States for 2000-2001. Teaching and Teacher Education, Vol. 24, 1173-1184.

National Center for Education Statistics. (2015). The Condition of Education 2015. Retrieved April 16, 2017, from nces.ed.gov/pubs2015/2015144.pdf

Ruhland, S. (2001). Factors influencing the turnover and retention of Minnesota's secondary career and technical education teachers. Proceedings of the $75^{\text {th }}$ Annual Meeting of the Association for Career and Technical Education. New Orleans, LA. December, 2001.
Scribner, J. P., Truell, A. D., Hager, D. R., \& Sricha, S. (2001). An exploratory study of career and technical education teacher empowerment: implications for school leaders. Journal of Career and Technical Education, 18(1), 46-57.

Stockard, J., \& Lehman, M. B. (2004). Influences on the satisfaction and retention of 1st-year teachers: the importance of effective school management. Educational Administration Quarterly, 40(5), 742771.

Strong, L. E. G., \& Yoshida, R. K. (2014). Teachers' autonomy in today's educational climate: current perceptions from an acceptable instrument. Educational Studies: Journal of the American Educational Studies Association, 50(2), 123-145.

Thomas, S. L. \& Heck, R. H. (2001). Analysis of large-scale secondary data in higher education research: Potential perils associated with complex sampling designs. Research in Higher Education, 42(5), 517-540.

Thomas, S. L., Heck, R. H., \& Bauer, K. W. (2005). Weighting and adjusting for design effects in secondary data analyses. New Directions for Institutional Research, 2005(127), 51-72.

Tourkin, S., Thomas, T., Swaim, N., Cox, S., Parmer, R., Jackson, B., Cole, C., \& Zhang, B. (2010). Documentation for the 2007-08 Schools and Staffing Survey (NCES 2010-332). U.S. Department of Education, Washington, DC: National Center for Education Statistics. Retrieved September 13, 2017 from https://nces.ed.gov/pubs2010/2010332_1 .pdf

Author

Bradley Bowen is an Assistant Professor in the School of Education's Integrative STEM Program, Virginia Tech, 207 War Memorial Hall, Blacksburg, VA 24061, (540) 231-5915, email: bowenb@vt.edu 
RUNNING HEAD: School Influence and Classroom Control

Adam Marx is an Assistant Professor in the School of Education's Teacher Education Program, North Dakota State University, FLC 210H, Fargo, ND 58108, (701) 231-7439, email: adam.marx@ndsu.edu

Thomas Williams is an Associate Professor in the School of Education's Special Education Program, Virginia Tech, 314 War Memorial Hall, Blacksburg, VA 24061, (540) 231-8337, email: thwilli1@vt.edu

Larry Napoleon is an Assistant Professor in the School of Education's Teacher Education Program, North Dakota State University, EML 155D, Fargo, ND 58108, (701) 231-7684, email: larry.napoleon@ndsu.edu

Manuscript originally submitted 07.27.2015, accepted for publication 01.05.2017, published 12.15.2017 